\title{
Foreknowledge, Freedom, and the Fixity of the Past
}

\author{
John Martin Fischer
}

Received: 30 January 2011 / Accepted: 23 February 2011 /

Published online: 18 March 2011

(C) The Author(s) 2011. This article is published with open access at Springerlink.com

\begin{abstract}
I seek to clarify the notion of the fixity of the past appropriate to Pike's regimentation of the argument for the incompatibility of God's foreknowledge and human freedom. Also, I discuss Alvin Plantinga's famous example of Paul and the Ant Colony in light of Pike's argument.
\end{abstract}

Keywords God's foreknowledge · Human freedom · Pike · Plantinga .

Paul and the Ant Colony

In his paper, "Divine Foreknowledge and Alternative Conceptions of Human Freedom," William P. Alston said:

Nelson Pike's important 1965 paper, 'Divine Omniscience and Voluntary Action,' presents an interestingly novel version of the old argument from divine foreknowledge to our inability to do (choose) other than what we in fact do.... This argument has stimulated a flurry of discussion that shows no signs of abating. ${ }^{1}$

Marilyn Adams published an important paper in the "flurry of discussion," and I also published a paper that discussed both Pike and Adams. ${ }^{2}$ In the footnote attached to the last sentence in the passage just quoted above, Alston goes on to say:

At the March 1984 Pacific Regional meeting of the Society of Christian Philosophers, Pike presented a discussion of Fischer's paper, which was responded to by Marilyn Adams and Fischer, so that the conferees were treated to hearing Adams on Pike on Fischer on Adams on Pike, and Fischer on Pike on Fischer on Adams on Pike. 'Enough!' you may well cry. And yet the beat goes on. ${ }^{3}$

\footnotetext{
${ }^{1}$ Alston (1985); reprinted in Fischer, ed. (1989), pp 258-73; the quotation is from pp. 258-9 in Fischer, ed., (1989).

${ }^{2}$ Adams, Marilyn. (1967); and Fischer (1983).

${ }^{3}$ Alston (1985); p. 323 in Fischer, ed., (1989).

J. M. Fischer $(\bowtie)$

Department of Philosophy, University of California, Riverside, Riverside, CA, USA

e-mail: john.fischer@ucr.edu
} 
Not surprisingly, a quarter of a century later there is still much work on the great problem of the relationship between God's foreknowledge and human freedom, and, in particular, on Pike's many important contributions to understanding this problem. ${ }^{4}$ The 1984 Pacific Regional meeting of the Society of Christian Philosophers took place at Westmont College, high in the hills above Santa Barbara. I am deeply honored to be participating again in a discussion of these issues - and Nelson Pikes' seminal contributions to them-on a beautiful campus on the edge of the Pacific Ocean with Marilyn and Robert Adams and so many other friends.

Nelson Pike's article, "Divine Omniscience and Voluntary Action," is one of the most influential pieces in contemporary Philosophy of Religion. ${ }^{5}$ Published over forty years ago, it has elicited many different kinds of replies. ${ }^{6}$ Here I will begin by laying out the argument for the incompatibility of God's foreknowledge and human freedom to do otherwise as presented by Pike, and I will focus on the crucial issue of the fixity of the past - the fundamental engine that drives the argument.

\section{Pike's Argument}

It will be useful to begin by having before us the central argument of Pike's paper. He claims that a selection of plausible (although admittedly contentious) assumptions about God's attributes implies that His existence (so conceived) is incompatible with human freedom, understood as involving genuine access to alternative possibilities (freedom to do otherwise).

Pike assumes that "God knows $X$ " entails "God believes $X$ " and " $X$ is true." Further, Pike holds that the individual who is God is essentially omniscient; that is, it is part of God's essence that He believes all and only true propositions. Additionally, God is assumed to be essentially "eternal" in the sense of being "sempiternal"; that is, it is part of God's essence that He exists at all times. Given the above assumptions, Pike presents an argument that he summarizes schematically as follows:

1. "God existed at $t 1$ " entails "If Jones did $X$ at $t 2$, God believed at $t 1$ that Jones would do $X$ at $t 2$."

2. "God believes $X$ " entails " $X$ ' is true."

3. It is not within one's power at a given time to do something having a description that is logically contradictory.

4. It is not within one's power at a given time to do something that would bring it about that someone who held a certain belief at a time prior to the time in question did not hold that belief at the time prior to the time in question.

5. It is not within one's power at a given time to do something that would bring it about that a person who existed at an earlier time did not exist at that earlier time.

6. If God existed at $t 1$ and if God believed at $t 1$ that Jones would do $X$ at $t 2$, then if it was within Jones's power at $t 2$ to refrain from doing $X$, then (1) it was within Jones's power at $t 2$ to do something that would have brought it about

\footnotetext{
${ }^{4}$ For a discussion of Pike's argument and the surrounding literature, see Fischer, Todd, and Tognazzini (2009).

${ }^{5}$ Pike (1965). Also, see Fischer (1992).

${ }^{6}$ Fischer, Todd, and Tognazzini (2009).
} 
that God held a false belief at $t 1$, or (2) it was within Jones's power at $t 2$ to do something which would have brought it about that God did not hold the belief He held at $t 1$, or (3) it was within Jones's power at $t 2$ to do something that would have brought it about that any person who believed at $t 1$ that Jones would do $X$ at $t 2$ (one of whom was, by hypothesis, God) held a false belief and thus was not God - that is, that God (who by hypothesis existed at $t 1$ ) did not exist at $t 1$.

7. Alternative 1 in the consequent of item 6 is false. (from 2 and 3 )

8. Alternative 2 in the consequent of item 6 is false. (from 4 )

9. Alternative 3 in the consequent of item 6 is false. (from 5)

10. Therefore, if God existed at $t 1$ and if God believed at $t 1$ that Jones would do $X$ at $t 2$, then it was not within Jones's power at $t 2$ to refrain from doing $X$. (from 6 through 9).

11. Therefore, if God existed at $t 1$, and if Jones did $X$ at $t 2$, it was not within Jones's power at $t 2$ to refrain from doing $X$. (from 1 and 10$)^{7}$

Pike says that premises (1) and (2) simply make explicit the doctrine of God's essential omniscience with which he is working, premises (3), (4), and (5) express part of the "logic of the concept of ability or power as it applies to human beings," and premise (6) is an "analytic truth." 8

It is fair to say that Pike's paper crystallized an argument for the incompatibility of God's omniscience and human foreknowledge that had been "around" for perhaps millennia in a way that sharpened it and rendered it clear that the argument need not rest on any sort of obvious logical fallacy. ${ }^{9}$ One might also say that Pike did for the argument for incompatibilism about God's foreknowledge and human freedom what such philosophers as Ginet, Wiggins, and Van Inwagen did for the importantly parallel argument for incompatibilism about causal determinism and human freedom. ${ }^{10}$ Additionally, Pike's regimentation of the argument helped to throw into relief different strategies of response, some of which he himself noted; the ateomporalist response (associated with Boethius and Aquinas), the Aristotelian response (now typically dubbed "Open Theism"), and the Ockhamist response. ${ }^{11}$

\section{An Alternative Formulation of the Argument}

I begin my brief analysis here by pointing out that there is nothing magic about the particular way in which Pike formulated the argument; the argument can be reformulated in various different ways that are arguably valid. Thus, if a philosopher

\footnotetext{
${ }^{7}$ Pike (1965), pp. 33-4.

${ }^{8}$ Pike (1965), pp. 34-5.

${ }^{9}$ Merricks (2009) has recently argued that while the best versions of the argument may not fall prey to the fatalist's fallacy, they nevertheless do employ a different sort of logical impropriety, namely begging the question. For a reply, see: Fischer and Todd (2011).

${ }^{10}$ Van Inwagen (1983), and Ginet (1990). For discussion of the parallels between the argument for incompatibilism about God's omniscience and human freedom and the argument for incompatibilism about causal determinism and human freedom, see Fischer (1994).

${ }^{11}$ Aristotle is often interpreted as denying bivalence with respect to future contingents, although this interpretation is controversial. Also, there are other versions of Open Theism: see Fischer, Todd, and Tognazzini (2009).
} 
objects to a particular aspect of the argument as presented by Pike, we need to consider whether the objection would also apply to other ways of capturing the basic intuitive ingredients in the argument. For example, consider the locution used by Pike, "bringing it about that p." It appears that Pike is relying on a "power entailment principle" that holds that if an agent has it in his power to bring it about that $p$, and if $p$ entails $q$, then the agent has it in his power to bring it about that $q .{ }^{12}$ But power entailment principles of this kind have been attacked by various philosophers. $^{13}$

It is however important to see that, even if such principles are problematic, Pike's argument can be developed without employing the notion of "bringing it about that $p$ " and thus without invoking any such principle_or any related principle. ${ }^{14}$ Here is just one such formulation of the argument (holding fixed the assumptions with which Pike works). First, we assume a principle capturing the intuitive idea that the past is fixed:

(FP): For any action $Y$, agent $S$, and time $t$, if it is true that if $S$ were to do $Y$ at $t$, some fact about the past relative to $t$ would not have been a fact, then $S$ cannot at $t$ do $Y$ at $t$.

(FP) captures the idea that if it is a necessary condition of performing an act that some fact about the past would not have been a fact, then one cannot perform the act.

I can now state the argument as follows:

Suppose that God exists and that $S$ does $X$ at $t 2$. Now one of the following conditionals must be true:

1. If $S$ were to refrain from doing $X$ at $t 2$, then God would have held a false belief at $t 1$.

2. If $S$ were to refrain from doing $X$ at $t 2$, then God would not have existed at $t 1$.

3. If $S$ were to refrain from doing $X$ at $t 2$, then God would have held a different belief from the one He actually held at $t 1$, i.e., God would have believed at $t 1$ that $S$ would refrain from doing $\mathrm{X}$ at $t 2$.

But (1) must be false, in virtue of God's essential omniscience. Further, if (2) were true, then it would follow that $S$ cannot refrain from doing $X$ at $t 2$. This would seem to follow from (FP); but even if it turned out that (FP) does not apply to (2) because of worries (to be discussed below) about what facts "count" as part of the past, it would seem that one could argue from God's counterfactual independence of possible human action to the conclusion that if (2) were true, then $S$ cannot refrain from doing $X$ at $t 2$. The idea behind God's counterfactual independence of possible human action is plausible: if God is the Supreme Being (and thus "worthy of worship"), it cannot be the case that his existence would hang on whether or not some ordinary human being performs some ordinary action. ${ }^{15}$ Finally, if (3) were

\footnotetext{
${ }^{12}$ See Hasker (1985).

${ }^{13}$ See, for example, Quinn (1985), Talbott (1985), and Hoffman and Rosenkrantz (1980).

${ }^{14}$ Fischer (1994), p. 63; also, see fn. 12 on pp. 248-9.

${ }^{15}$ One could formulate a principle capturing the notion of God's counterfacutal independence of possible human action: (CI): For any action $Y$, agent $S$, and time $t$, if God exists and if it is true that if $S$ were to do $Y$ at $t$, God would not exist, then $S$ cannot at $t$ do $Y$ at $t$.
} 
true, then it would seem to follow in virtue of (FP) that $S$ cannot refrain from doing $X$ at $t 2$. (Again, I say, "seems to follow", because of possible worries as to what counts as part of the past, for the purposes of [FP].) ${ }^{16}$

I contend that this version of the argument crystallizes the basic intuitive elements of Pike's argument in a way that does not depend on a power entailment principle. Further, the argument (or a slightly modified version thereof) appears to be valid. ${ }^{17}$ Thus, the objections to the Pike's argument based on worries about the power entailment principles can be seen to be relatively superficial. ${ }^{18}$

\section{The Fixity of the Past}

Now consider again the revised the principle I proposed above about the past:

(FP): For any action $Y$, agent $S$, and time $t$, if it is true that if $S$ were to do $Y$ at $t$, some fact about the past relative to $t$ would not have been a fact, then $S$ cannot at $t$ do $Y$ at $t$.

It emerged from Pike's interesting discussion (subsequent to the appearance of "Divine Foreknowledge and Voluntary Action") with John Turk Saunders that Pike had something very much like (FP) in mind. ${ }^{19}$ In "Of God and Freedom", Saunders distinguished a causal from a non-causal sense of "bringing about", and he further contended that it is only the non-causal sense that is relevant to Pike's argument. The non-causal sense, when it is employed in locutions asserting that an individual can bring about the truth of some actually false proposition about the past, gives rise to what has become known as "counterfactual power over the past". In Pike's reply to Saunders, "Of God and Freedom: A Rejoinder," Pike made it clear that he had intended the non-causal sense of "bringing about", and thus that he had intended to deny that any human agent could have at a time counterfactual power over God's beliefs (or anyone's beliefs) at a prior time. Pike says:

... I shall reformulate the principle so as to eliminate the phrase "bring about" (which I did not intend as a causal notion, but which might be interpreted as such). I shall adopt Saunders' way of talking (it may be clearer than my own) and affirm as an apriori principle;

(4) It is not within one's power at a given time so to act that someone (God or otherwise) who held a certain belief at a time prior top the time in question did not hold that belief at the time prior to the time in question.

Saunders has argued that the following principle is false-namely:

It is not within one's power at a given time so to act that the past would have been other than it was.

\footnotetext{
${ }^{16}$ Fischer (1994), pp. 62-3.

${ }^{17}$ Fischer (1996).

${ }^{18}$ For another version of the argument, see: Fischer (1994), pp. 88-93.

19 Saunders (1966) and Pike (1966).
} 
...The principle I used (Principle 4) is not of this unrestricted type. It does not cover just any fact about the past. It is restricted to cases in which beliefs were held at a given time in the past - a specific class of 'hard facts' about the past. $^{20}$

I shall return to this point below, but I note here that Pike restricts the principle not just to hard facts about the past, but, as he says, "a specific class of 'hard facts' about the past." In the same paper - the rejoinder to Saunders-Pike had introduced his famous (but problematic) distinction between two types of facts about the past:

On the one hand, let us say that some facts about the past (for example, facts about Caesar's death) were 'fully accomplished,' 'over-and-done-with,' and so forth in the past (for example, in 44 B.C.). These are sometimes called 'hard facts' about the past. The fact that Caesar died on the steps of the Senate is a fact of this sort. On the other hand, some facts about the past are not, relative to a given time, 'fully accomplished,' 'over-and-done-with,' and so forth at that time. The fact that Caesar died 2009 years before the writing of Saunders' paper is a fact of this sort. Before Saunders wrote his paper, the fact that Caesar died 2009 years before he wrote his paper was not a 'fully accomplished' fact about Caesar's death. Of course, this formula will not do as a technical device, but I think it will suffice for present purposes. I think I can limp to the point I want to make using only our pre-analytical understanding of the distinction herein suggested. ${ }^{21}$

So Pike was suggesting a restriction of (FP) at least to hard facts about the past. How exactly to characterize the hard/soft fact distinction has given rise to a large literature, but note that Pike himself wished to stick with a "pre-analytical understanding" of what is already 'fully accomplished' and 'over-and-done-with' versus what is not; given this, he thought he could "limp to the point" he wanted to make.

It is also very important to note that Pike's distinction between hard and soft facts about the past pertains to different kinds of facts about the past (and whether they are, intuitively speaking, 'over-and-done-with' or not). This is not the same distinction as the distinction between what is "fixed" and out of any agent's power to affect and what is not. No small measure of confusion has been caused by a failure to keep the two distinctions analytically separate: the distinction between hard and soft facts, and the distinction between fixed facts (at the relevant times) and those that are not fixed (at those times). Note that Ockham's notion of "accidental necessity" is fixity that arises precisely from hardness of the past; whereas fixity may come from other sources, accidental necessity is fixity that stems specifically from the over-and-done-with nature of hard facts about the past. ${ }^{22}$

The restricted version of the fixity of the past principle that incorporates Pike's distinction between hard and soft facts is:

\footnotetext{
${ }^{20}$ Pike (1966), pp. 370-71.

${ }^{21}$ Pike (1966), p. 370.

${ }^{22}$ For a further discussion of different sources of fixity, see Fischer (1994), especially pp. 111-30.
} 
(FPh): For any action $Y$, agent $S$, and time $t$, if it is true that if $S$ were to do $Y$ at $t$, some hard fact about the past relative to $t$ would not have been a fact, then $S$ cannot at $t$ do $Y$ at $t$.

It is perhaps natural to think that (FPh) is the restricted principle of the fixity of the past that Pike endorses and that plays the relevant role in Pike's argument. But in his rejoinder to Saunders, Pike makes it clear that he has in mind an even more restricted principle. Recall that Pike said that the principle he has in mind is restricted to "a specific class of 'hard facts' about the past." Pike thus makes it clear that the principle that drives his argument is doubly restricted; it pertains not just to the hard facts about the past, but to a specific sub-class of them.

Whereas I find the restriction to hard facts eminently plausible, I find the additional restriction to a proper sub-class of such facts very puzzling. After all, if hard facts are over-and-done-with, and if this property grounds their fixity, how can only a proper-subclass of the hard facts be fixed? After all, all hard facts, by their very nature, are "fully accomplished" and "over-and-done-with". It is plausible that this feature of them is what grounds their fixity; but then all hard facts should be deemed equally fixed. Pike's double restriction is, then, highly puzzling. It leaves us in a position in which we need either a different sort of explanation of the fixity of hard facts - that is, an explanation that does not invoke "over-and-done-with-ness" at all —or an account of why only some over-and-done with facts are fixed.

I do not here contend that there could not be a completely different approach to explaining why hard facts are fixed, but I have always found it plausible that their fixity comes from their being over-and-done with. ${ }^{23}$ Given that hard facts about the past are already fully accomplished, they have no "handles" now. Perhaps one is here thinking of temporal and spatial distance as analogous; just as I cannot now pick up a coffee cup that is sitting on a table in Rochester, New York (since I am in Southern California), I cannot now do anything about the fact that Caesar died on the steps of the Senate; spatial and temporal distance function similarly to deprive me of getting a grasp on the relevant things. Without any further explanation, Pike's double restriction seems arbitrary and, at best, mysterious.

It is interesting that in his original article, Pike never formulated or invoked any general (or even restricted) principle of the fixity of the past. He simply relied on what he took to be an apriori truth to the effect that no one can at a time so act that someone would not have believed at a prior time what he in fact believed at that prior time. But it is really unsatisfying simply to assert this as an apriori truth; why exactly is it true at all? To answer this question, it seems most natural to invoke something about the fixity of the past. ${ }^{24}$

\footnotetext{
${ }^{23}$ For a fascinating discussion of alternative approaches to explaining the nature and fixity of hard facts about the past, see Todd (unpublished).

${ }^{24}$ Marilyn Adams has suggested to me (in conversation) an interesting explanation of Pike's stance here. At the time of writing his original paper, Pike was at Cornell, which was much under the influence of Wittgenstein and his followers (such as Max Black and Norman Malcolm). Perhaps Pike's reliance on a putatively apirori truth about the fixity of past beliefs, rather than a more general (and "grander") principle about the fixity of hard facts about the past, reflects a kind of Wittgensteinian conservatism.
} 


\section{Examples from Saunders and Plantinga}

In the reply to Saunders Pike explicitly makes the distinction between hard and soft facts and also commits himself to a doubly-restricted fixity-of-the-past principle. Better to understand at least Pike's motivation for his double-restriction, it will be helpful to have before us an example offered by John Turk Saunders:

Suppose that, at $\mathrm{t} 1$, I decide to skip at $\mathrm{t} 2$ rather than run at $\mathrm{t} 2$, that conditions are 'normal' at $\mathrm{t} 1$ and $\mathrm{t} 2$ (I have not been hypnotized, drugged, threatened, manhandled, and so forth), and that I have the ability (know-how) both to skip and to run. Suppose, too, that the world happens to be governed by empirical laws such that, if ever a man in my particular circumstances were to make a decision of this kind, then he would not change his mind and do something else but would follow through on his decision: suppose, that is, that, under the circumstances which prevail at $\mathrm{t} 1$, my decision is empirically sufficient for my skipping at $\mathrm{t} 2$. Clearly, it is in my power to run at $\mathrm{t} 2$, since I know how to do so and the conditions for the exercise of this ability are normal. If I were to exercise this power then I would not, at $\mathrm{t} 1$, have decided to skip at $\mathrm{t} 2$ or else the circumstances at $\mathrm{t} 1$ would have been different. Hence my power to run is the power so to act that an earlier situation would have been other than in fact it is. ${ }^{25}$

Pike's reply to Saunders' example is instructive. First, he makes the important point that, in the scenario offered by Saunders, it is not at all clear that it was in his power at $t 2$ to run at $t 2$. He says:

One feature of [Saunders'] reasoning strikes me as highly suspicious. If the world were such that it was physiologically, psychologically impossible for me to run at $t 2$ (given my skipping-decision and conditions $C$ at $t 1$ ) it is not at all clear that it was within my power at $t 2$ to run. There may be some sense of 'free' in which an action is free whenever it is the carrying out of the agent's earlier decision, but in the situation Saunders describes (where the skipping decision at $t 1$ is 'empirically sufficient' for skipping at $t 2$ ), it is hard to see that an action free (in this sense) would, of necessity, be one with respect to which it was within the agent's power to do otherwise. I shall not, however, pursue this point. ${ }^{26}$

Pike could have added that it is not clear in Saunders' example that if the relevant agent were to run at $\mathrm{t} 2$, the past would have been different in the indicated way (i.e., the agent would have decided at $\mathrm{t} 1$ to run at $\mathrm{t} 2$ ). Perhaps the agent would have forgotten his or her previous decision, or acted against the previous decision, and so forth. So it is not so clear that the backtracking counterfactual is true in the case. But if one insists that the backtracker is true, this casts considerable doubt on the truth of the paired "can-claim" - the claim that the agent can at $\mathrm{t} 2$ run at $\mathrm{t} 2$, despite having decided at $\mathrm{t} 1$ to skip at $\mathrm{t} 2$. The hypothesized truth of the backtracker marks this as an unusual case - a case in which ordinary intuitions might be unreliable.

\footnotetext{
${ }^{25}$ Saunders, (1966), p. 221

${ }^{26}$ Pike (1966), p. 375
} 
Actually, I find this a powerful reply, and I wish that Pike had indeed pursued it. Indeed, Pike suggests just the kind of elaboration I would have liked to see. More specifically, Pike points out essentially that Saunders is not entitled to move quickly from the fact that typically we have it in our power - or we suppose that we do, apart from any special assumptions, such as that God exists and has foreknowledge of our actions - either to run or not run at a given time to the conclusion that we have this sort of power in this particular context. As I pointed out above, the context is specialit is so constructed that the only way in which one could run would be so to act that some hard fact about the past would not have been a fact. But we do not typically suppose that in an ordinary case our running (rather than not running) would require such an alteration of the hard features of the past; thus, whatever we are inclined to think about an "ordinary" case cannot be transposed precipitously into the case constructed by Saunders. After all, in Pike's original informal presentation of his argument, he said:

Last Saturday afternoon, Jones mowed his lawn. Assuming that God exists and is (essentially) omniscient in the sense outlined above, it follows that (let us say) eighty years prior to last Saturday afternoon, God knew (and thus believed) that Jones would mow his lawn at that time. But from this it follows, I think, that at the time of action (last Saturday afternoon) Jones was not able - that is, it was not within Jones's power - to refrain from mowing his lawn. ${ }^{27}$

Here it is obvious that Pike does not take it that it follows from the mere fact that we typically would suppose that we have the power either to mow or not mow at a given time that we do in fact have this power, in the scenario in which refraining from mowing would require an alteration of some hard fact about the past. The whole point is that Pike's argument is supposed to be a "skeptical argument", parallel in this respect to the Consequence Argument. Further, the relevant notion of power is not a "general capacity" or "know-how"; again, it is uncontentious that we have the general capacity and "know-how" to refrain from mowing our lawns, even in the scenario described by Pike (in which God has foreknowledge that we will in fact mow at the relevant time). Given what Pike clearly presupposes about mowing and not mowing (under the envisaged circumstances), he should say exactly the same thing about running or not running in Saunders' case. Saunders' case does not seem to me to be relevantly different; here, as in Pike's case of mowing or not mowing, there is a challenge to our commonsense view of ourselves as having freedom to do otherwise. The challenge is that, despite this commonsense view, it turns out that such freedom would require-in the specific circumstances in question - the power so to act that hard facts about the past would not have been facts.

Of course, as I pointed out above, Pike does state that he "wants to say" that in Saunders' case the agent does not have the power to run at $t 2$. Pike however instead goes on to emphasize that even if one grants Saunders that the agent can indeed run at $t 2$ in his example, this would not threaten his doubly-restricted fixity-of-the past principle:

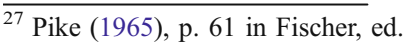


Nowhere have I claimed (or presupposed) that it is never within one's power so to act that a 'hard fact' about the past would have been other than it was. The principle I used in my paper (Principle 4) was even more restricted that was pointed out above. I claimed (as an apriori truth) that it is never within one's power so to act that a belief held at an earlier time would not have been held at that earlier time. Thus, even if we accept the reasoning used in Saunders' skiprun example (which I am not ready to do), he has shown only that it could be within one's power (at a given time) so to act that a decision made in the past (relative to that time) would not have been made. ... His argument is thus rigidly restricted to the case in which the determining 'hard fact' about the past is a decision of the agent. ... Saunders' counterexample, in other words, is not a counterexample to Principle $4 . .{ }^{28}$

But I would press the point that it seems arbitrary to distinguish between the fixity of past beliefs and decisions. If fixity comes from over-and-done-with-ness, then if past beliefs are fixed, then past decisions should also be fixed. ${ }^{29}$ The doublerestriction appears arbitrary and remains entirely puzzling to me, absent some alternative explanation of the fixity of hard facts (that is, an alternative to the claim that fixity derives from being over-and-done-with).

So Pike should have stuck with the simpler, more elegant reply to Saunders, and he should have explicitly embraced a singly-restricted fixity-of-the-past principle, such as (FPh). The ingredients were certainly all there in Pike's work, and, in fairness, he did reply to Saunders in the way I have recommended, without elaborating on it. Perhaps we should not hold it against Pike that he explored and even seemed in the end to endorse an alternative route to the same conclusion.

Finally, I turn to an example that has attracted considerable attention-Alvin Plantinga's example of "Paul and the Ant Colony" (Plantinga: 1986). It turns out that all the ingredients necessary to understand this example properly were assembled by Pike in his rejoinder to Saunders; the analysis of Paul and the Ant Colony should be exactly parallel to the analysis of Saunders' skip-run example. Here is Plantinga's example:

Let us suppose that a colony of carpenter ants moved into Paul's yard last Saturday. Since this colony has not yet had a chance to get properly established, its new home is still a bit fragile. In particular, if the ants were to remain and Paul were to mow his lawn this afternoon, the colony would be destroyed. Although nothing remarkable about these ants is visible to the naked eye, God, for reasons of his own, intends that it be preserved. Now as a matter of fact, Paul will not mow his lawn this afternoon. God, who is essentially omniscient, knew in advance, of course, that Paul will not mow his lawn this afternoon; but if he had foreknown instead that Paul would mow this afternoon, then he would have prevented the ants from moving in. The facts of the matter, therefore, are these: if Paul were to mow his lawn this afternoon,

\footnotetext{
${ }^{28}$ Pike (1966), p. 376.

${ }^{29}$ There may indeed be a difference between beliefs and decisions with respect to our control of them prior to their occurrence; but I do not see how this difference would translate into a difference with respect to the fixity of past decisions and beliefs.
} 
then God would have foreknown that Paul would mow his lawn this afternoon; and if God had foreknown that Paul would mow this afternoon, then God would have prevented the ants form moving in. So if Paul were to mow his lawn this afternoon, then the ants would not have moved in last Saturday. But it is within Paul's power to mow this afternoon. There is therefore an action he can perform such that if he were to perform it, then the proposition [that the colony of carpenter ants moved into Paul's yard last Saturday] would have been false. ${ }^{30}$

Various philosophers - typically at or connected with Notre Dame! - simply take it for granted that Plantinga's example of Paul and the Ant Colony is a case in which an agent has it in his power to perform an act which is such that, if he were to perform it, a hard fact about the past would not have been a fact. But I have always been puzzled by this, since it is obviously contentious whether (in the specific circumstances in question) Paul does indeed have the power to mow his lawn this afternoon! The dialectical situation is exactly as in Saunders' skip-run example and indeed in the original presentation of Pike's argument. The whole point of a skeptical argument - such as the Consequence Argument (in the context of causal determinism) or Pike's argument (in the context of God's foreknowledge) is to put into doubt whether we have the power to do otherwise with respect to ordinary actionsactions with respect to which we typically assume that we can do otherwise (apart from special assumptions, such as that causal determinism obtains or a certain sort of God exists). It is obviously not dialectically kosher simply to assume, in Plantinga's example, that Paul has the power (in the relevant sense) to mow. (Of course, he has the general capacity to mow-but this is not the notion of power in question.)

Plantinga appears to import ordinary intuitions about our powers into a context in which he is not entitled to bring such intuitions; he thus instantiates a philosophical version of the powerful Freudian psychological mechanism of "transference". As with at least some instances of Freudian transference, this move is inappropriate. That is, one cannot simply import ordinary views about our powers into the philosophical context of an evaluation of the argument for the incompatibility of God's foreknowledge and human freedom - a skeptical argument that explicitly challenges these ordinary views about powers. As with Saunders' example, from the mere fact that Paul has the skills and "how-how" to mow, it does not follow that he can mow, in the sense of "can" that is at stake. The kind of power in question is, after all, necessary and sufficient for the freedom-relevant condition on moral responsibility; simply having a general capacity (relevant skills and know-how) is not sufficient for the power in question, since one might have the general capacity while being blocked from exercising it in various ways - and thus not morally responsible for failing to exercise it.

Plantinga is simply not entitled to assume from the outset that Paul has the power (in the relevant sense) to mow his lawn. If Plantinga were entitled to this claim, then there would be a very simple answer to Pike's argument: one could simply say that obviously Jones has the power to refrain from mowing his lawn last Saturday morning, although he did mow his lawn and God knew eighty years ago that he

\footnotetext{
${ }^{30}$ Plantinga (1986); reprinted in Fischer, ed. (1989); the quotation is on pp. 200-1- of Fischer, ed. (1989)
} 
would mow his lawn. Something has obviously gone wrong here, and I contend that it is Plantinga's gratuitous importation of commonsense assumptions about powers into a context in which those assumptions are precisely what is at issue. Philosophical transference can be as toxic as Freudian transference. The point about transference is, I believe, the Wittgensteinean point that we should be very careful about moving from one "language game" to another - a point on which Pike would surely have insisted.

\section{A Reply on Behalf of Plantinga (and Saunders)}

In the discussion above, I have worked within the framework adopted by Pike and Saunders, modified and generalized a bit. More specifically, I have worked with $(\mathrm{FPh})$, in part because Pike and Saunders accept something like this principle — or should, upon reflection (in Pike's case). But perhaps Plantinga would reject (FPh) in favor of a "possible-worlds" way of capturing the intuitive idea of the fixity of the past:

(FPpw) For any action $Y$, agent $S$, and time $t, S$ can perform $Y$ at $t$ only if there is a possible world with the same "hard" past up to $t$ as the actual world in which $S$ does $Y$ at $t .^{31}$

By "actual world" here I simply mean the world in which it is alleged that $S$ has the ability in question.

Plantinga could point out that in his example of Paul and the Ant Colony, Paul can mow his lawn this afternoon (according to [FPpw]) insofar as there is a possible world with the same set of hard facts about the past (including the fact that the ants moved into Paul's yard last Saturday) in which Paul mows. This is completely compatible with the truth of the backtracking counterfactual, "If Paul had mown his lawn this afternoon, then the ants would not have moved in last Saturday." The crucial point is that the can-claim and the counterfactual correspond to two different modal notions; the semantics for the relevant claims point us to different possible worlds. That is, the semantics for the counterfactual points us to the nearest possible worlds in which Paul mows his lawn this afternoon; in these possible worlds the ants would not have moved in last Saturday. In contrast, the can-claim merely points us to worlds in which all the hard facts about the past are the same as in the actual world; these worlds need not be the same as those relevant to the backtracker. And, compatibly with the truth of the backtracker, there can be a possible world in which Paul mows his lawn this afternoon and also the ants moved in last Saturday. Thus, on (FPpw), it does not seem that Plantinga's example is obviously problematic (in the way indicated in the previous section); that is, on (FPpw), the mere fact of the truth of the backtracker does not bear in any way on the truth of the can-claim. ${ }^{32}$ And, of course, the same analysis applies, mutatis mutandis, to Saunders' skip/run example.

\footnotetext{
${ }^{31}$ See Fischer (1994), p. 90. There is an extended discussion of the differences between (FPh) and (FPpw) in Fischer (1994).

${ }^{32}$ For further elabotation and analysis of these issues, see Fischer (1994), pp. 87-110.
} 
The first thing to say about this move is that it is not obvious to me that (FPpw) is to be preferred to $(\mathrm{FPh})$; this would need an argument. But putting this point to the side, it seems to me that the examples do not in any way impugn Pike's original argument, adjusted so as now to rely on (FPpw). That is, putting aside issues about what to say about Paul and the Ant Colony and Saunder's skip/run example, it should be clear that (FPpw) is just as potent in the argument for incompatibilism as (FPh). Thus, the originial motivaton of Saunders' example would be thwarted; also, insofar as one wished to invoke Paul and the Ant Colony as a way of calling into question Pike's argument, this would be futile.

To see this, consider the following brief and informal presentation of Pike's argument, suitably modified so that it relies on (FPpw). Make the same assumptions about God as in Pike's original argument and also start (as above) with the assumption that $S$ does $X$ at t2. It follows that God believed at t1 that $S$ would do $X$ at t2. On the assumption that God's prior beliefs are hard facts about the past, it follows from (FPpw) that $S$ can refrain from doing $X$ at t2 only if there is some possible world in which $S$ refrains from doing $X$ at t2 and also God believed at t1 that $S$ would do $X$ at t2. But given God's essential omniscience, there is no so possible world. Thus, $S$ cannot at t1 refrain from doing $X$ at $t 2$.

Thus, quite apart from whether Saunders or Plantinga has produced an uncontroversial example in which some agent can at a given time so act that some hard fact about the past relative to that time would not have been a fact, it can be seen that Pike's argument - or an appropriate modification of it - still has force. The examples are really quite beside the point, if they are intended to impugn the basic thrust of incompatibilism. Of course, the argument still depends on the contention that God's prior beliefs are indeed hard facts about the past, and this is controversial. My point here is not that the incompatibilist's argument is obviously and uncontroversially sound; it is, rather, that the examples of Saunders and Plantinga do not constitute problems for it.

\section{Conclusion}

Nelson Pike's great 1965 paper, "Divine Omniscience and Voluntary Action," has contributed significantly to our understanding of one of the great traditional problems in philosophy of religion, and, indeed, in philosophy generally: the problem of understanding the relationship between an omniscient God and human freedom (and moral responsibility). In this paper I have focused my attention on what I take to be the fundamental idea that drives the argument for the incompatibility of God's foreknowledge and human freedom: the fixity of the past. Perhaps it is fair to say that in the first few decades after the publication of Pike's paper, most of the literature discussing it focused on the Ockhamist approach to replying to the argument; in more recent years, I think the focus has shifted to Open Theism and various approaches to responding to the argument inspired by Open Theism. ${ }^{33}$ Currently, there is a resurgence of interest in the argument, and I am aware of very promising new work on it by contemporary philosophers, such as Michael

$\overline{{ }^{33} \text { Fischer, Todd, and Tognazzini }}$ (2009). 
Rea, Alicia Finch, Dean Zimmerman, Garrett Pendergraft, Justin Coates, and Patrick Todd (among others). Some of this work-especially by Patrick Todd-seeks to apply insights from contemporary work on the metaphysics of dependence and also philosophy of time to Pike's argument (and, more generally, the incompatibilist's argument). I also think that there are promising connections between sophisticated recent work on the Consequence Argument and the argument for the incompatibility of God's foreknowledge and human free will; they are, after all, parallel arguments.

So I am excited to report that the beat continues to go on! I am confident that Nelson Pike and William Alston would be pleased by the sustained interest in this great set of issues. To borrow another lyric from Sonny and Cher's old song (from which Alston had borrowed the refrain), "History has turned the page." With the passing of Nelson Pike and also William Alston, history has indeed turned the page. But as Sonny and Cher also said, "Drums keep pounding a rhythm to the brain... The beat goes on, the beat goes on..."34

Open Access This article is distributed under the terms of the Creative Commons Attribution Noncommercial License which permits any noncommercial use, distribution, and reproduction in any medium, provided the original author(s) and source are credited.

\section{References}

Adams, M. (1967). Is the existence of God a 'Hard' fact? The Philosophical Review, 76, 492-503. reprinted in Fischer, ed., 1989, pp. 74-85.

Alston, W. (1985). Divine foreknowledge and alternative conceptions of human freedom. International Journal for Philosophy of Religion, 18, 19-32. reprinted in Fischer, ed, 1989, pp. 258-73.

Fischer, J. M. (1983). Freedom and foreknowledge. The Philosophical Review, 92, 67-79. reprinted in Fischer, ed., 1989, pp. 86-96.

Fischer, J. M. (Ed.). (1989). God, foreknowledge, and freedom. Stanford: Stanford University Press).

Fischer, J. M. (1992). Recent work on god and freedom. American Philosophical Quarterly, 29, 91-109.

Fischer, J. M. (1994). The metaphysics of free will: An essay on control. Oxford: Blackwell.

Fischer, J. M. (1996). A new compatibilism. Philosophical Topics, 24, 49-66.

Fischer, J. M, \& Todd, P. (2011). The truth about freedom: A reply to merricks. The Philosophical Review Fischer, J. M., Todd, P., \& Tognazzini, N. A. (2009). Re-reading Nelson Pike's, 'Divine Omniscience and Voluntary Action'. Philosophical Papers, 38, 247-270.

Ginet, C. (1990). On action. Cambridge: Cambridge University Press.

Hasker, W. (1985). Foreknowledge and necessity. Faith and Philosophy, 2, 121-157. reprinted in Fischer, ed., (1989), pp. 216-57.

Hoffman, J., \& Rosenkrantz, G. (1980). Philosophical Studies, 37, 289-296.

Merricks, T. (2009). Truth and freedom. The Philosophical Review, 118, 29-57.

Pike, N. (1965). Divine omniscience and voluntary action. The Philosophical Review, 74, 27-46. reprinted in John Martin Fischer, ed. (1989), pp. 57-73.

Pike, N. (1966). Of God and freedom: a rejoinder. The Philosophical Review, 75, 369-379.

Plantinga, A. (1986). On Ockham's way out. Faith and Philosophy, 3, 235-69. reprinted in John martin Fischer, ed. (1989), pp. 178-215.

Quinn, P. L. (1985). Plantinga on foreknowledge and freedom. In J. E. Tomberlin \& P. van Inwagen (Eds.), pp. 271-287.

Saunders, J. T. (1966). Of God and freedom. The Philosophical Review, 75, 219-225.

Talbott, T. B. (1985). On divine foreknowledge and bringing about the past. Philosophy and Phenomenological Research, 46, 455-469.

Van Inwagen, V. (1983). An essay on free will. Oxford: Clarendon.

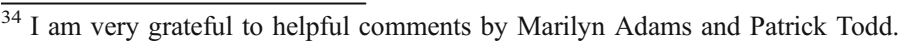

